\title{
Peningkatan Nilai Tambah Produk Olahan Gula Aren Melalui Inovasi Kemasan dan Pemanfaatan Media Sosial Sebagai Strategi Pemasaran di Desa Aik Bual Kecamatan Kopang
}

\author{
Novia Rizki Warismayati*1, Halimatul Ulfa Ru' ${ }^{1}{ }^{1}$, Windi Irawati ${ }^{2}$, \\ Baiq Novianti Dili Hairunnisa ${ }^{3}$ \\ ${ }^{1}$ Fakultas Teknologi Pangan dan Agroindustri, Universitas Mataram, Mataram, \\ ${ }^{2}$ Fakultas Peternakan, Universitas Mataram, Mataram \\ ${ }^{3}$ Fakultas Ekonomi dan Bisnis, Universitas Mataram, Mataram
}

\section{Article history}

Received: 15 Maret 2020

Revised: 25 Maret 2020

Accepted: 11 Mei 2020

*Corresponding Author:

Novia Rizki Warismayati

Fakultas Teknologi Pangan dan Agroindustri, Universitas

Mataram,

Mataram, NTB,

Indonesai;

Email:

Rizkinovia7991@gmail.com.

\begin{abstract}
Aik Bual village is located in Kopang sub-district, Central Lombok district. In this village, there are many palm trees that grow in gardens and forests. Most of the people use palm sugar to be processed into palm sugar. Palm sugar production by the Aik Bual community is carried out individually in their homes and there is also a joint business group (KUBE) that has been formed and already has a certificate from the village namely KUBE Salanumpang Aren. The aim of this program is to increase the added value of processed palm sugar products through packaging innovation and the use of social media as a marketing strategy. The method used is socialization, counseling, as well as training and assisting producers of palm sugar business groups. Furthermore, the socialization event took place at the Aik Bual Village Office, which was attended by a joint business group of Salanumpang Aren who are Aik Bual people as active actors in making palm sugar, while the activity was attended by parties from the village such as Village Owned Enterprises (BUMDes) and village officials. Through this program it is hoped that the community, especially KUBE Salanumpang Aren in Aik Bual Village, will be able to increase the added value of processed palm sugar products through packaging innovation and the use of social media as a marketing strategy in Aik Bual Village, Kopang sub-district.
\end{abstract}

Keywords: Palm; Sugar; Marketing; Packaging

Abtrak: Desa Aik Bual terletak di kecamatan Kopang, kabupaten Lombok Tengah, yang banyak terdapat pohon aren yang tumbuh di Kebun dan Hutan. Sebagian besar masyarakat memanfaatkan nira aren untuk diolah menjadi gula aren. Produksi gula aren dilakukan secara individu di rumahnya masing-masing dan ada pula kelompok usaha bersama (KUBE), salah satunya KUBE Salanumpang Aren. Tujuan dari program ini adalah untuk meningkatkan nilai tambah produk olahan gula aren melalui inovasi kemasan dan pemanfaatan media sosial sebagai strategi pemasaran. Metode yang digunakan adalah sosialisasi, penyuluhan, dan pelatihan serta pendampingan produsen kelompok usaha gula aren, bertempat di Kantor Desa Aik Bual yang dihadiri oleh kelompok usaha bersama Salanumpang Aren yang merupakan masyarakat Aik Bual sebagai pelaku aktif pembuat gula aren,dan diikuti oleh aparat desa seperti BUMDes dan aparat desa. Melalui program ini diharapkan masyarakat khususnya KUBE Salanumpang Aren di Desa Aik Bual mampu meningkatkan nilai tambah produk olahan gula aren melalui inovasi kemasan dan pemanfaatan media sosial sebagai strategi pemasaran di Desa Aik Bual kecamatan Kopang.

Kata kunci: Gula; Aren; Pengemasan; Pemasaran 


\section{PENDAHULUAN}

Pembangunan pertanian saat ini diarahkan kepada pembangunan pertanian yang berorientasi agribisnis, berwawasan lingkungan dan mampu menunjang upaya pengentasan kemiskinan serta peningkatan kualitas sumberdaya manusia. Pengembangan potensi sumberdaya alam suatu kawasan mempunyai nilai strategis. Pembangunan pertanian melalui pengembangan komoditas perkebunan ataupun komponen agroforestri yang potensial di suatu wilayah merupakan salah satu upaya untuk meningkatkan perekonomian wilayah, yang pada akhirnya akan meningkatkan daya saing wilayah tersebut. Desa Aik Bual merupakan salah satu dari 11 desa yang ada di wilayah Kecamatan Kopang Kabupaten Lombok Tengah. Desa Aik Bual ini terdiri dari 7 dusun, diantaranya dusun Rabuli, dusun Bual, dusun Ramus, dusun Bare Eleh, dusun Nyeredep, dusun Talun Ambon, dan dusun Pertanian. Secara geografis wilayah Desa Aik Bual berbatasan dengan Desa Wajageseng di sebelah Selatan, di sebelah Barat berbatasan dengan Desa Setiling, di sebelah Timur berbatasan dengan Desa Jenggik Utara, dan di sebelah Utara berbatasan dengan Hutan Lindung. Desa Aik Bual merupakan salah satu desa yang banyak ditumbuhi tanaman aren. Sebagaian besar masyarakat memanfaatkan nira aren untuk diolah menjadi gula aren. Oleh karena itu desa Aik Bual dikenal dengan salah satu desa penghasil gula aren di Lombok Tengah.

Sebagian besar masyarakat di Desa Aik Bual mengandalkan hasil produksi nira aren yang diolah menjadi gula aren sebagai penopang kebutuhan hidupnya. Produksi gula aren oleh masyarakat Aik Bual dilakukan secara individu di rumahnya masing-masing dan ada pula kelompok usaha bersama (KUBE) yang telah terbentuk dan sudah memiliki sertifikat dari desa yaitu KUBE Salanumpang Aren.

Produksi gula aren pada umumnya berbentuk seperti tabung. Ada juga sebagian masyarakat mengolahnya menjadi gula semut. Gula aren dan gula semut tersebut dijual di pasar tradisonal, dan dibeli juga oleh masyarakat sekitar.

Tingginya permintaan gula aren membuat harganya cukup menguntungkan bagi penghasil gula aren. Gula aren, terutama gula semut merupakan salah satu produk yang memiliki nilai ekonomis dan memiliki potensi yang sangat bagus untuk dikembangkan. Gula aren yang berasal dari Indonesia dapat diterima oleh pasar ekspor karena aromanya yang khas dan memiliki kandungan sukrosa yang lebih tinggi. Menurut Burhanuddin (2005), kekhasan gula aren dibandingkan dengan gula lainnya karena mengandung kadar sukrosa lebih tinggi (84\%), dibanding gula tebu (20\%) dan gula bit (17\%).

Kurangnya inovasi pengemasan produk terutama gula aren menjadi kendala bagi masyarakat setempat dalam mengoptimalkan nilai ekonomi produk tersebut agar menjadi produk lokal unggulan. Salah satu upaya yang dapat dilakukan adalah memperkenalkan inovasi pengemasan gula aren. Oleh karena itu dirasa perlu dilakukan pelatihan yang ditujukan kepada masyarakat di Desa Aik Bual tentang inovasi pengemasan gula aren sehingga membantu masyarakat setempat meningkatkan nilai ekonomisnya.

Kendala lainnya adalah strategi pemasaran yang masih minim oleh masyarakat di desa Aik Bual. Berdasarkan hasil observasi di Desa Aik Bual, masyarakat yang memproduksi gula aren hanya memasarkan produk tersebut di pasar tradisional dan masyarakat setempat. Untuk itu perlunya edukasi dan pelatihan terkait strategi pemasaran produk gula aren agar mencapai penjualan yang maksimal hingga mencapai pasar Internasional. Oleh karena itu, telah dilakukan dan dilaksanakan program Kuliah Kerja Nyata (KKN) yang berupa bantuan dalam bentuk jasa pendampingan dan bimbingan selama kurang lebih 45 hari.

\section{METODE}

Pemberdayaan Masyarakat merupakan suatu proses bertahap yang harus dilakukan dalam rangka memperoleh dan meningkatkan daya sehingga masyarakat mampu mandiri (Winarni, 1998). Pemberdayaan memiliki makna membangkitkan sumber daya, kesempatan, pengetahuan, dan keterampilan masyarakat untuk meningkatkan kapasitas dalam menentukan masa depan mereka (Suparjan dan Hempri, 2003).

Berdasarkan permasalahan yang diuraikan di atas, maka beberapa solusi yang telah dilakukan adalah sosialisasi, penyuluhan, serta pelatihan dan pendampingan pada produsen kelompok usaha gula semut. Sesuai dengan target luaran, maka dilakukan pengumpulan data dengan menggunakan metode observasi. 
Pelaksanaan kegiatan pengabdian kepada masyarakat ini menggunakan metode pendekatan sosial yang menempatkan masyarakat binaan sebagai subyek kegiatan dan metode kaji terap partisipatif (Participatory Action Reseach) pada tahap pelatihan kelompok tani binaan, dan praktik demonstrasi pemilahan mutu produk sekaligus paking (packaging) dan pelebelan produk untuk percepatan alih teknologi dan pembinaan langsung oleh tim KKN.

Kegiatan sosialisasi, penyuluhan, dan pelatihan serta pendampingan dilakukan mulai bulan Desember 2019 sampai Februari 2020 yang bertempat di Kantor Desa Aik Bual dan rumah ketua kelompok usaha bersama (KUBE) Salanumpang Aren yang terletak di Dusun Nyeredep Desa Aik Bual Kecamatan Kopang, Kabupaten Lombik Tengah.

\section{Tahap Persiapan}

Tahap persiapan melakukan survei pendahuluan untuk mengidentifikasi khalayak sasaran, program kerja yang akan dilakukan dan metode pelatihan.

\section{Tahap Pelaksanaan}

Tahap pelaksanaan ada beberapa kegiatan yang dilakukan yaitu sosialisasi, penyuluhan, serta pelatihan dan pendampingan:

1. Sosialisasi Program Kerja

Sosialisasi program kerja dilakukan untuk memberi tahu masyarakat khususnya KUBE Salanumpang Aren tentang kegiatan yang akan dilakukan untuk meningkatkan nilai tambah produk gula aren.

2. Penyuluhan Kewirausahaan Produk Gula Aren

Penyuluhan kewirausahaaan produk gula aren dilakukan untuk menanamkan jiwa wirausaha kepada kelompok usaha bersama Salanumpang Aren. Meningkatkan lapangan kerja yang diharapkan setiap anggota kelompok bisa mendirikan usahanya sendiri dan memberikan pekerjaan bagi warga sekitar khususnya masyarakat Desa Aik Bual.

3. Penyuluhan Izin Usaha Gula Aren

Penyuluhan izin usaha gula aren dilakukan untuk memberi tahu kelompok usaha bersama Salanumpang Aren tentang cara untuk mendapatkan nomor pangan industri rumah tangga (P-IRT).

4. Pelatihan dan Pendampingan Teknik Pengemasan Gula Aren

Pelatihan dan pendampingan teknik pengemasan gula aren dilakukan untuk memberikan pengetahuan cara pengemasan produk gula aren untuk meningkatkan nilai jual.

5. Pelatihan dan Pendampingan Teknik Pemasaran Melalui Media Sosial

Pelatihan dan pendampingan teknik pemasaran melalui media sosial dilakukan untuk memberikan pengetahuan tentang cara mempromosikan produk gula semut secara online sesuai dengan tuntutan industri 4.0.

\section{HASIL DAN PEMBAHASAN}

Desa Aik Bual Kecamatan Kopang memiliki luas wilayah \pm 2.517 .189 , yang sudah memiliki izin 100 Ha, dan sedang dalam proses perizinan 350 Hektar $\left(45.000 \mathrm{~m}^{2}\right)$. Desa Aik Bual adalah salah satu desa yang disebelah utaranya terdapat hutan lindung, maka sebagian besar tumpuan lahan merupakan lahan perkebunan dan persawahan, fasilitas umum maupun permukiman. Selain perkebunan, dari jumlah luas lahan tersebut adapun rincian penggunaan lahan meliputi perkebunan 1.336.120 Ha, Persawahan 479.392 Ha, pemukiman $701.677 \mathrm{Ha}$.

Sebagian besar masyarakat di desa Aik Bual mengandalkan hasil produksi nira aren yang diolah menjadi gula aren dan gula semut sebagai penopang kebutuhan hidupnya. Produksi gula aren pada umumnya berbentuk seperti tabung. Ada juga sebagian masyarakat mengolahnya menjadi gula semut. Gula aren dan gula semut tersebut dijual di pasar tradisonal, dan dibeli juga oleh masyarakat sekitar. 
Faktor-faktor yang menyebabkan banyak orang memilih bekerja sebagai pembuat gula aren karena di samping banyaknya pohon aren yang terdapat di hutan, pembuatan gula aren juga dapat dikerjakan oleh lakilaki maupun perempuan dan tidak harus meninggalkan rumah.

Upaya untuk meningkatkan nilai jual produk dan memperluas pemasaran produk gula aren, maka kami mengadakan beberapa program kegiatan untuk pemberdayaan masyarakat Desa Aik Bual, tentang penyuluhan kewirausahaan produk gula aren, penyuluhan izin usaha gula aren, pelatihan dan pendampingan teknik pengemasan gula aren, dan pelatihan dan pendampingan teknik pemasaran melalui media sosial. Program tersebut merupakan suatu cara meningkatan nilai tambah produk olahan gula aren melalui inovasi kemasan dan pemanfaatan media sosial sebagai strategi pemasaran di desa aik bual kecamatan kopang. Kegiatan ini difokuskan pada kelompok usaha bersama salanumpangaren di Dusun Nyeredep.

\section{Sosialisasi program kerja}

Pelaksanaan kegiatan sosialisasi bertempat di Kantor Desa Aik Bual. Kegiatan sosialisasi ini diikuti oleh kelompok usaha bersama Salanumpang Aren yang merupakan masyarakat Aik Bual sebagai pelaku aktif pembuat gula aren, adapun kegiatan ini diikuti oleh pihak dari desa seperti Badan Usaha Milik Desa (BUMDes) dan aparat desa.

Materi sosialisasi diantaranya mengenai penyuluhan kewirausahaan produk gula aren, pengenalan bentuk cetakan baru produk gula aren, dan penyuluhan izin usaha untuk produk gula aren yang dipaparkan oleh tim KKN Tematik UNRAM 2019/2020. Sosialisasi ini diadakan untuk menumbuhkan dan meningkatkan kesadaran masyarakat akan pentingnya inovasi baru untuk meningkatkan ekonomi dari masyarakat dari Desa Aik Bual itu sendiri.

\section{Pelatihan dan pendampingan teknik pengemasan gula aren}

Program kerja selanjutnya yaitu pelatihan dan pendampingan teknik pengemasan gula aren yang bertempat di rumah ketua kelompok usaha bersama salanumpang aren yang terletak di dusun nyeredep.

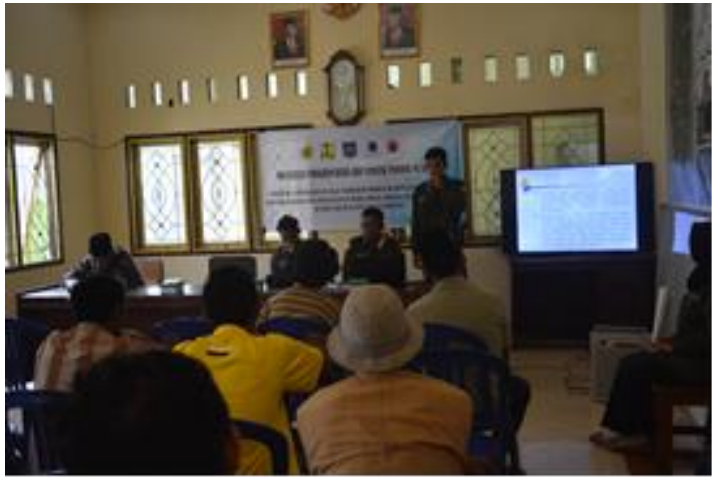

Gambar 1. Pelaksanaan Sosialisasi program kerja

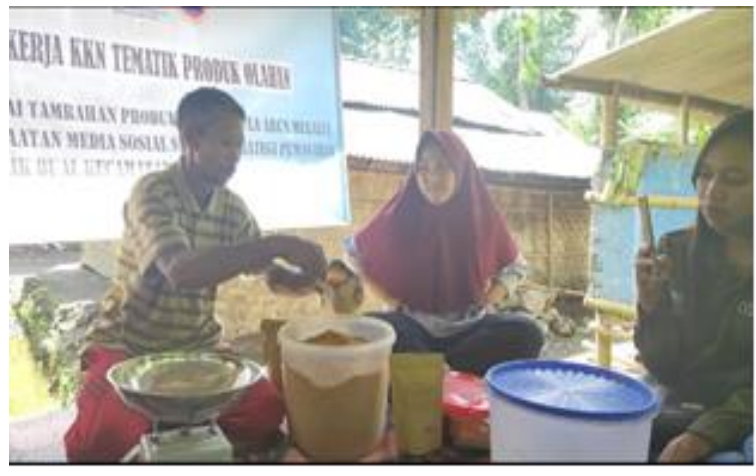

Gambar 2. Pelatihan dan Pendampingan Teknik Pengemasan Gula Aren

Pengemasan dilakukan dengan cara manual yang dimulai dengan menimbang gula semut sebanyak 250 gram dan dimasukkan ke dalam kemasan. Kemasan yang digunakan berbentuk standing pouch.

KUBE Salanumpang Aren telah memiliki kemasan sendiri yang diproleh dari binaan pihak BNPB dan UNRAM, namun kemasan tersebut belum dapat membedakan kualitas gula semut tersebut, sehingga kami menambahkan stiker yang dapat digunakan sebagai pembeda kualitas yang terdiri dari 4 tingkatan kualitas yaitu super+, super, medium, dan standar. 


\section{Pelatihan dan Pendampingan Teknik Pemasaran Melalui Media Sosial}

Selanjutnya yaitu program kerja pelatihan dan pendampingan teknik pemasaran melalui media sosial bertempat di rumah ketua kelompok usaha bersama salanumpang aren yang terletak di Dusun Nyeredep.

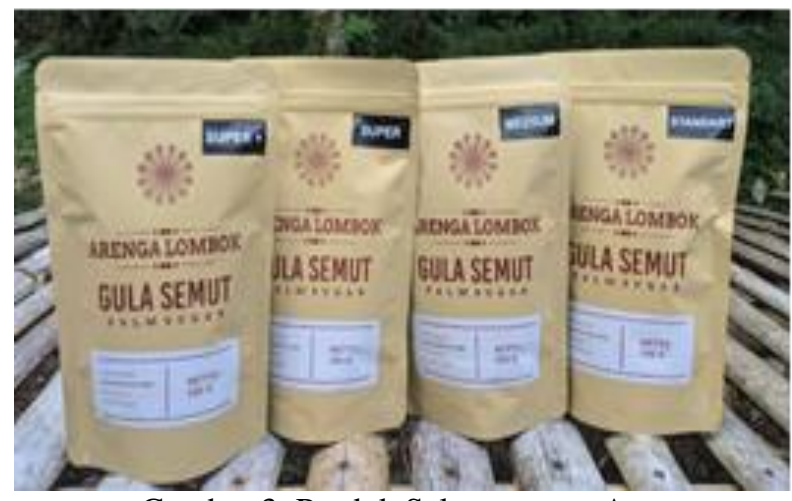

Gambar 3. Produk Salanumpang Aren

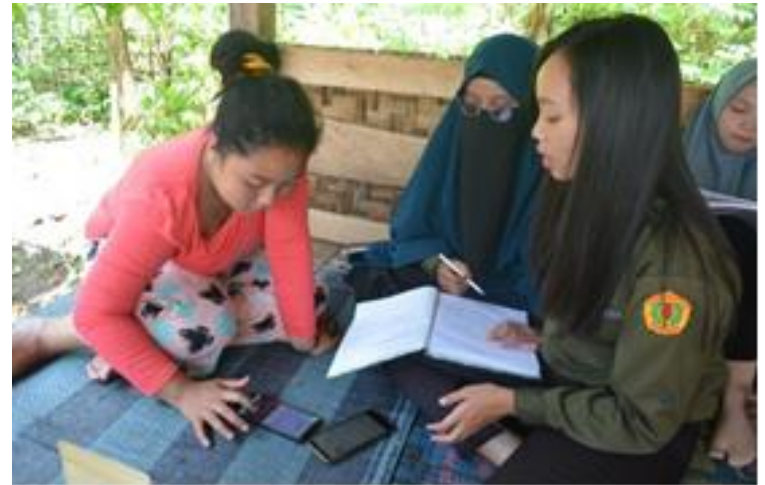

Gambar 4. Pelatihan dan Pendampingan Teknik Pemasaran Melalui Media Sosial

Sebelumnya kelompok usaha bersama salanumpang aren ini hanya memiliki akun google bisnis yang dibuatkan saat mengikuti binaan BNPB dan UNRAM namun google bisnis belum banyak digunakan oleh masyarakat sehingga kami menggunakan media sosial seperti facebook melalui fitur marketplace dan pembuatan akun serta pemasaran melalui instagram.

\section{KESIMPULAN DAN SARAN}

Sebagian besar masyarakat di Desa Aik Bual mengandalkan hasil produksi nira aren yang diolah menjadi gula aren sebagai penopang kebutuhan hidupnya. Produksi gula aren oleh masyarakat Aik Bual dilakukan secara individu dan kelompok. Kurangnya inovasi pengemasan dan pemasaran produk gula aren menjadi kendala bagi masyarakat setempat dalam mengoptimalkan nilai ekonomi produk tersebut agar menjadi produk lokal unggulan. Upaya untuk meningkatkan nilai jual produk dan memperluas pemasaran produk gula aren, melalui pemberdayaan masyarakat yang diserta penyuluhan kewirausahaan produk gula aren, penyuluhan izin usaha gula aren, pelatihan, dan pendampingan teknik pengemasan gula aren, serta pelatihan dan pendampingan teknik pemasaran melalui media sosial, telah dihasilkan produk gula aren dalam berbagai kualitas. Peningkatan pendapatan dapat dicapai melalui pemilahan kualitas produk.

\section{Ucapan Terima Kasih}

Disampaikan kepada bapak Dr. Bambang Budi Santoso, atas segala bimbingan dan arahannya selama kegiatan KKN dan penyelesaian pelaporan kegiatan.

\section{DAFTAR PUSTAKA}

Burhanuddin. 2005. Prospek pengembangan usaha kompresi dalam produksi gula aren. Jakarta.

Kurniawan, H., Ansar, K. Yuniarto, dan F. I. Khalil. 2018. Introduksi teknologi pengemasan gula aren di desa kekait kabupaten lombok barat. Jurnal Widiabakti 1(1): 118-123.

Kurniawan, H., Bintoro, N., Karyadi, Joko N. W. 2018. Pendugaan umur simpan gula semut dalam kemasan dengan pendekatan arrhenius. Jurnal Ilmiah rekayasa pertanian dan biosistem. 6(1): 93-99. 